\title{
All-optical delay technique for supporting multiple antennas in a hybrid optical - wireless transmission system
}

Prince, Kamau; Chiuchiarelli, A; Presi, M; Tafur Monroy, Idelfonso; Ciaramella, E

Published in:

21st Annual Meeting of the IEEE Lasers and Electro-Optics Society, 2008. LEOS 2008.

Link to article, DOI:

10.1109/LEOS.2008.4688500

Publication date:

2008

Document Version

Publisher's PDF, also known as Version of record

Link back to DTU Orbit

Citation (APA):

Prince, K., Chiuchiarelli, A., Presi, M., Tafur Monroy, I., \& Ciaramella, E. (2008). All-optical delay technique for supporting multiple antennas in a hybrid optical - wireless transmission system. In 21st Annual Meeting of the IEEE Lasers and Electro-Optics Society, 2008. LEOS 2008. IEEE. https://doi.org/10.1109/LEOS.2008.4688500

\section{General rights}

Copyright and moral rights for the publications made accessible in the public portal are retained by the authors and/or other copyright owners and it is a condition of accessing publications that users recognise and abide by the legal requirements associated with these rights.

- Users may download and print one copy of any publication from the public portal for the purpose of private study or research.

- You may not further distribute the material or use it for any profit-making activity or commercial gain

- You may freely distribute the URL identifying the publication in the public portal 


\title{
All-Optical Delay Technique for Supporting Multiple Antennas in a Hybrid Optical - Wireless Transmission System
}

Kamau Prince (1), Andrea Chiuchiarelli (2), Marco Presi (2), I. Tafur Monroy (1) and Ernesto Ciaramella (2)

1 : DTU Fotonik, Tech. Univ. Denmark, Kgs. Lyngby, DK-2800 Denmark. kpri@fotonik.dtu.dk

2 : Scuola Superiore Sant'Anna, via Moruzzi 1, Pisa 56124, Italy. andrea.chiuchiarelli@cnit.it

\begin{abstract}
We introduce a novel continuously-variable optical delay technique to support beam-forming wireless communications systems using antenna arrays. We demonstrate delay with 64-QAM modulated signals at a rate of $15 \mathrm{Msymbol} / \mathrm{sec}$ with $2.5 \mathrm{GHz}$ carrier frequency.
\end{abstract}

\section{Introduction}

Rapid increases in the coverage and speed of optical communications networks, combined with recent increases in the coverage and throughput of wireless access networks, has motivated a desire for increased data bandwidth delivery via the convergence of hybrid optical/wireless communications networks. This has motivated interest into the integration and transmission of radiofrequency (RF) signals over fiber optic infrastructure [1]. To increase the throughput of the air interface while maintaining high spectral efficiency, newer-generation wireless access networking schemes, including mobile WiMAX (based on IEEE 802.16e) and the latest draft of the wireless IEEE 802.11n LAN standard, will implement RF signal transmission supporting (and with $802.11 \mathrm{n}$ requiring) multiple transceiver antennas at either end of the wireless link. This allows increased data throughput by exploitation of statistical properties of the wireless channel response. Such arrayed-antenna schemes can support the steering of the wireless RF beam to maximize received energy at the remote transceiver, or implement simultaneous communication paths via multiple active antennas at each terminal.

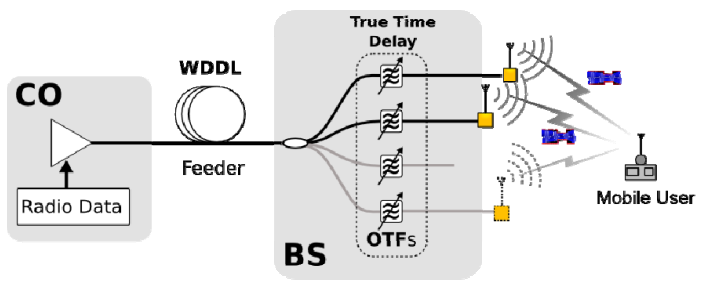

Figure 1: Proposed system concept: wideband optical source, wavelength-dependent delay line (WDDL) and Optical Tunable filter (OTF) achieve tunable alloptical delay. The resulting radio beam from the antenna array is steered towards the mobile user.

Previously, multiple-antenna radio over fiber delivery schemes typically utilized more complex schemes, implementing switched discrete optical delay [2] or multiple optical sources [3]. We propose an alternative converged ROF access scheme, which integrates native support for multiple access antennas, while retaining the other advantages of optical distribution systems [4]: our proposed system is shown on the left of Fig. 1. We demonstrate the achievement of all-optical true-time delay of a $2.5 \mathrm{GHz}$ RF signal modulated reflecting SOA (RSOA), optical tunable filter (OTF) and wavelength-dependent delay line (WDDL) and report on successfully transmission, delay and recovery of the pore and modulated carrier wave. This protocol-independent scheme supports a wide variety of modulation formats and implements the delay required for full $2 \pi$ beam steering of a $2.5 \mathrm{GHz}$ radio wave, with appropriately spaced antennas. We obtained results indicating an unmodulated phase noise below $-100 \mathrm{dBc}$ at $1 \mathrm{kHz}$ offset for the output carrier, and good results with 64 QAM modulation.

\section{Experimental Setup}

In this system, the message modulates a wideband optical signal which propagates through a wavelength-dependent delay line: optical filtering is done to select the desired differential time delay between radiating antennas and achieve beamsteering of the transmitted RF signal as presented in Figure 1. The experimental setup is shown in Fig. 2.

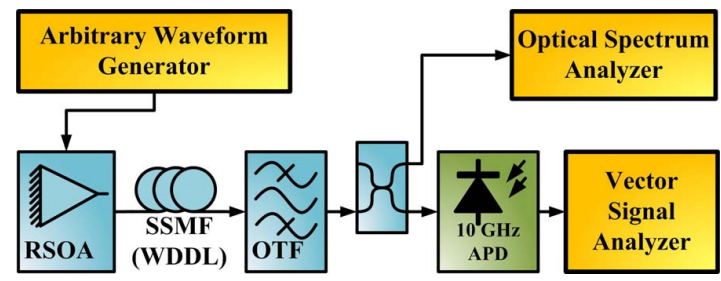

Figure 2: Experiment layout diagram.

The wideband amplified spontaneous emission (ASE) noise output of a RSOA is directly modulated by an RF signal with a $2.5 \mathrm{GHz}$ carrier frequency. The RSOA was a commercial device, providing $22 \mathrm{~dB}$ small-signal gain and $0 \mathrm{dBm}$ output saturation power when biased at $70 \mathrm{~mA}$ at $18^{\circ} \mathrm{C}$ temperature. The ASE had $20 \mathrm{~nm}$ FWHM and provided $-3 \mathrm{dBm}$ total output power with a peak at approximately $1549 \mathrm{~nm}$. The signal propagated through a WDDL implemented with $2.1 \mathrm{~km}$ standard SMF (17 ps $/ \mathrm{nm} \bullet \mathrm{km}$ dispersion) and a 2 nm FWHM OTF: a $10 \mathrm{GHz}$ APD was used at the receiver. The RF signal was generated with an 
Agilent E4438C ESG generator and evaluated with a 26.5 GHz Agilent N9020 MXA Signal Analyzer.

\section{Results}

Figure 3 reports the measurement of the true-timedelay (TTD) as a function of the filter detuning. We observe an exact linear relation over the whole filter bandwidth. The TTD is independent of OTF bandwidth. We assessed the noise performance of the system by evaluating phase noise at the system output (dashed, blue) for an unmodulated input: the results are reported in Fig. 4. The phase-noise of the input RF tone (solid, black) is also reported for comparison. These results indicate that the phase noise degradation through the system is below $20 \mathrm{~dB}$. We additionally note that the output phase noise was less than $-100 \mathrm{dBc} / \mathrm{Hz}$ at a $1 \mathrm{kHz}$ offset.

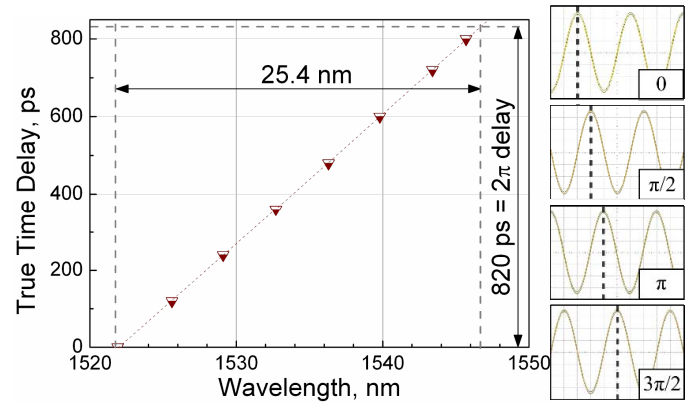

Figure 3: Showing delay vs. OTF central wavelength Sample delayed RF waveforms (right) show low attenuation over delay range.

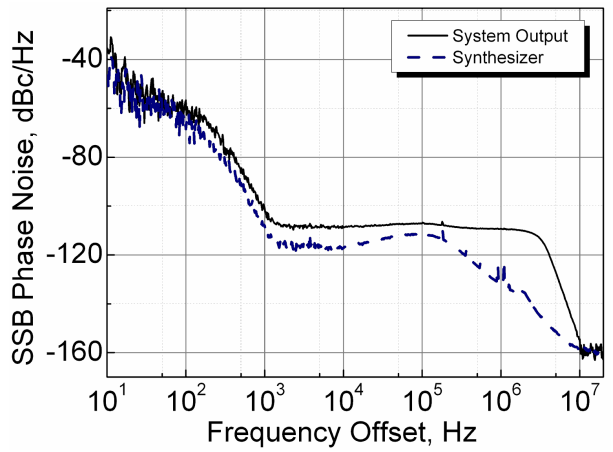

Figure 4: Single-sideband (SSB) phase noise variation with offset frequency, at input and output.

We then assessed system performance with 64-QAM modulation at a rate of $15 \mathrm{Msymbol} / \mathrm{second}$ (Msps) and an input RF power of $+11 \mathrm{dBm}$ : Fig. 5 shows the post photodetection RMS error vector magnitude (EVM) as a function of the wavelength detuning. Over the $26 \mathrm{~nm}$ detuning wavelength range of interest, we obtained EVM values below $2.5 \%$, which is well below the $3.1 \%$ RMS EVM requirement for single-channel WiMAX transmissions using this modulation format. We anticipate that lower signaling rates would be associated with improved performance.
Figure 6(a) presents the post-detection constellation and Fig. 6(b) present the Q-symbol eye diagram. These show reliable symbol demodulation and the clear eye opening indicates good system transmission performance. The SNR penalty incurred by transmission through this system is approximately $11.5 \mathrm{~dB}$, and enables us to place a bound on the SNR requirements at the input to this transmission to support WiMAX compliant communications.

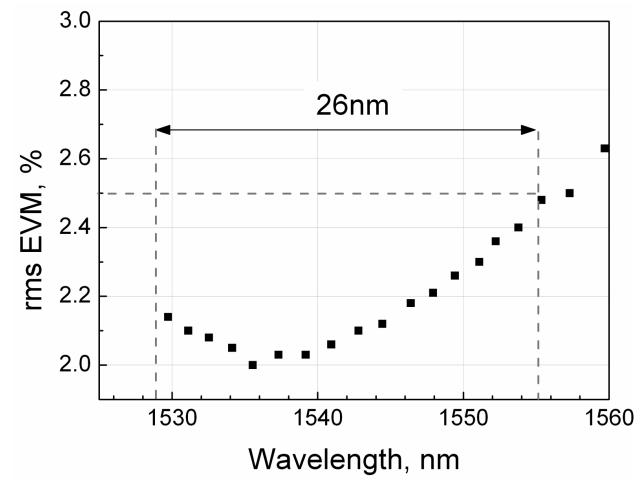

Figure 5: RMS EVM as a function of wavelength detuning for 64-QAM at $15 \mathrm{Msps}$ (90Mbps). This EVM profile follows the inverted power profile of the RSOA.

This OTF prevented testing below $1529 \mathrm{~nm}$.
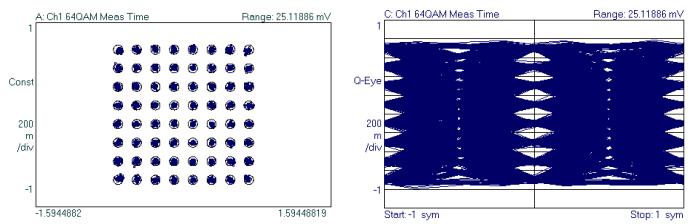

Figure 6: Output 64-QAM constellation (a, left) and $Q$ symbol eye diagram (b, right).

\section{Conclusions}

We have successfully demonstrated radio over fiber transmission system implementing all-optical delay. We transmitted a $2.5 \mathrm{GHz}$ RF signal modulated at 64 QAM over the system and obtained an RMS EVM of $2.5 \%$ at a signaling rate of $15 \mathrm{Msps}$ (corresponding to $90 \mathrm{MBps}$ ). The system supports multiple-antenna schemes and is potentially compatible with a wide range of transmission schemes

\section{Acknowledgments}

The authors gratefully acknowledge Marco Pagano of Agilent Technologies for use of the N9020 MXA Vector signal analyzer and E4438C ESC Generator.

\section{References}

1. Vegas Olmos et al. PTL, vol 20, pp 617-9 (2008)

2. Vidal et al. Electron. Lett., vol 39, pp 547-9 (2003)

3. Jofre et al. IEEE Trans. Antennas Propag., vol 56, pp 1594-1604 (2008)

4. Capmany et al. Nat. Phot., vol 1, pp 319-30 (2007) 